\title{
Participant characteristics and self-reported weight status in a cross-sectional pilot survey of self-identified followers of popular diets: Adhering to Dietary Approaches for Personal Taste (ADAPT) Feasibility Survey
}

\author{
Micaela C Karlsen ${ }^{1,2}$ (0), Alice H Lichtenstein ${ }^{3}$, Christina D Economos ${ }^{4}$, Sara C Folta ${ }^{4}(\mathbb{0}$, \\ Remco Chang $^{5}$, Gail Rogers ${ }^{6}$, Paul F Jacques ${ }^{1,6}{ }^{(1)}$, Kara A Livingston ${ }^{6}$ and \\ Nicola M McKeown ${ }^{1,6, *}$ \\ 'Nutritional Epidemiology Program, Tufts University Friedman School of Nutrition Science and Policy, Boston, MA, \\ USA: ${ }^{2}$ Applied Nutrition and Global Public Health, University of New England, Biddeford, ME, USA: ${ }^{3}$ Cardiovascular \\ Nutrition Laboratory, Jean Mayer USDA Human Nutrition Research Center on Aging at Tufts University, Boston, MA, \\ USA: ${ }^{4}$ Nutrition Interventions Program, Tufts University Friedman School of Nutrition Science and Policy, Boston, MA, \\ USA: ${ }^{5}$ Department of Computer Science, School of Engineering at Tufts University, Medford, MA 02155, USA: \\ ${ }^{6}$ Nutritional Epidemiology Laboratory, Jean Mayer USDA Human Nutrition Research Center on Aging at Tufts \\ University, Boston, MA 02111 , USA
}

Submitted 4 June 2019: Final revision received 4 February 2020: Accepted 6 April 2020: First published online 27 July 2020

\begin{abstract}
Objective: To describe characteristics of self-identified popular diet followers and compare mean BMI across these diets, stratified by time following diet.

Design: Cross-sectional, web-based survey administered in 2015.

Setting: Non-localised, international survey.

Participants: Self-selected followers of popular diets ( $n$ 9019) were recruited to the survey via social media and email announcements by diet community leaders, categorised into eight major diet groups.

Results: General linear models were used to compare mean BMI among (1) shortterm ( $<1$ year) and long-term ( $\geq 1$ year) followers within diet groups and (2) those identifying as 'try to eat healthy' (TTEH) to all other diet groups, stratified by time following the specific diet. Participants were $82 \%$ female, 93\% White and $96 \%$ non-Hispanic. Geometric mean BMI was lower $(P<0.05$ for all) among longerterm followers ( $\geq 1$ year) of whole food, plant-based (WFPB), vegan, whole food and low-carb diets compared with shorter-term followers. Among those following their diet for $1-5$ years $\left(n\right.$ 4067), geometric mean BMI $\left(\mathrm{kg} / \mathrm{m}^{2}\right)$ were lower $(P<0.05$ for all) for all groups compared with TTEH $\left(26.4 \mathrm{~kg} / \mathrm{m}^{2}\right)$ : WFPB $\left(23.2 \mathrm{~kg} / \mathrm{m}^{2}\right)$, vegan $\left(23.5 \mathrm{~kg} / \mathrm{m}^{2}\right)$, Paleo $\left(24.6 \mathrm{~kg} / \mathrm{m}^{2}\right)$, vegetarian $\left(25.0 \mathrm{~kg} / \mathrm{m}^{2}\right)$, whole food $\left(24.6 \mathrm{~kg} / \mathrm{m}^{2}\right)$, Weston A. Price $\left(23.5 \mathrm{~kg} / \mathrm{m}^{2}\right)$ and low-carb $\left(24.7 \mathrm{~kg} / \mathrm{m}^{2}\right)$.

Conclusion: Our findings suggest that BMI is lower among individuals who made active decisions to adhere to a specific diet, particularly more plant-based diets and/or diets limiting highly processed foods, compared with those who simply TTEH. BMI is also lower among individuals who follow intentional eating plans for longer time periods.
\end{abstract}

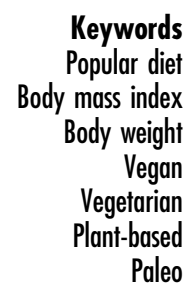

A growing segment of the public identifies as following a specific popular diet for a variety of reasons, including to improve health, prevent chronic disease or lose weight ${ }^{(1,2)}$. A popular diet can be defined as a dietary pattern promoted through cookbooks, diet books or popular media coverage, as opposed to a researcher-generated dietary pattern such as the Dietary Approaches to Stop Hypertension (DASH) $\operatorname{diet}^{(3)}$. Data from specialised retail food products $^{(4)}$, Google keyword search activity (see Appendix $1)^{(5)}$ and certain consumer surveys ${ }^{(6,7)}$ confirm there is ongoing interest in particular diets. These diets include vegan/vegetarian, Paleo, low-carb and a variety of "whole 
food' diets focused on avoiding highly processed foods. Although many popular diets differ in some respects, most share a common emphasis on eating practices generally associated with better health outcomes, including eating more fruits, vegetables ${ }^{(8)}$ and whole grains ${ }^{(9)}$, and limiting refined grains ${ }^{(10)}$ and foods high in added sugar ${ }^{(11)}$. Dietary guidelines recommend moving towards a more unrefined, plant-based diet given that the majority of adult Americans have intakes below the recommended goals for vegetables ( $87 \%$ ), fruits (75\%) and whole grains (92\%), while exceeding the recommendations for added sugars (70\%), saturated fat $(71 \%)$ and $\mathrm{Na}(89 \%)^{(12)}$

A variety of eating patterns have been reported to be beneficial for weight loss and reduced cardiometabolic risk, including plant-based ${ }^{(13)}$, Mediterranean ${ }^{(14)}$, vegan/ vegetarian $^{(15)}$, Paleo ${ }^{(16)}$, low-carb ${ }^{(17)}$ or gluten-free ${ }^{(18)}$. Given the high prevalence of overweight and obesity associated with typical US dietary intake patterns ${ }^{(19,20)}$, studying individuals who report long-term adherence to diets lower in refined foods, higher in fibre and containing more fruits and vegetables can provide important examples of lifestyle choices that may support higher dietary quality or healthier weight. However, to date, no observational study has captured data from individuals who selfreport adhering to a variety of popular diets and examined the association of these diets with BMI. Such data are relevant for dietitians and other health professionals who may encounter patients who either follow a specific popular diet or are interested in trying such diets to make specific dietary changes to achieve weight loss. Moreover, as interest in these diets for weight loss is encouraged by the popular media, health professionals should be prepared to engage in evidence-based discussion on such specific eating patterns.

The present study uses data from the Adbering to Dietary Approaches for Personal Taste (ADAPT) Feasibility Survey (FS) to examine the relationship between adherence to popular diet patterns and BMI. The first objective was to describe characteristics of self-identified popular diet followers, and the second objective was to compare mean BMI values across these diets, stratified by time following diet. Our hypothesis was that diet followers who identified as following a particular diet would have a lower BMI compared with those reporting that they 'try to eat healthy' (TTEH), and BMI would be lower among those participants reporting following their particular diet for a longer time period.

\section{Materials and methods}

As described in our previously published methodology paper $^{(21)}$, the ADAPT FS was a brief, web-based, crosssectional survey designed to recruit self-identified popular diet followers and capture certain demographic and lifestyle characteristics. The study sample included self-selected individuals $\geq 18$ years who encountered a study invitation through social media posts and newsletters shared by public figures promoting specific popular diets who acted as study recruitment partners. Participants answered yes to two screening questions 'Are you at least 18?' and 'Do you agree to participate'. Answering 'yes' to these two questions were the only requirements for participation. We provided the recruitment partners with text to share via social media, as previously described ${ }^{(21)}$. Enrolment was open for 8 weeks (14 July 2015-14 September 2015), with an active recruitment period of 6 weeks (14 July 2015-31 August 2015). The study was administered out of the Jean Mayer USDA Human Nutrition Research Center on Aging at Tufts University located in Boston, Massachusetts. The Checklist for Reporting Results of Internet E-Surveys (CHERRIES) was used to guide the survey design and administration ${ }^{(22)}$.

\section{Data captured}

In total, 9726 individuals responded to the survey. Of these, 9582 (98\%) provided complete data on age, sex, race and Hispanic ethnicity and indicated they followed a specific diet. The general principles of the self-reported diets are described in Table 1. Participants self-identified their current diet by responding to the question described in Fig. 1. The list of popular diet answer choices was based on our knowledge of the field and on recent Google Trends data (see online supplementary material, Supplemental Table 1) to track online search activity patterns with respect to a broad range of popular diets ${ }^{(21)}$. The term 'TTEH' was offered as a choice for those interested in healthy eating but who did not identify as following a specific diet ${ }^{(21)}$. Individuals who selected the 'no particular diet' ( $n$ 126) and 'unknown/prefer not to answer' ( $n$ 46) options, or who selected 'other' and were coded as 'avoidance $\&$ medical diet' ( $n$ 352) or 'weight loss or athletic diets' ( $n$ 39) constituted less than $4 \%$ ( $n$ 563) of the total sample and were excluded from analysis due to lack of specificity and/or limited sample size. The resulting sample size was 9019 participants for the characterisation of followers of popular diets (Objective 1 ). Due to missing ( $n 445$ ) or implausible ( $n$ 340) height or weight data, or missing data for time on diet $(n 8)$, the final sample size for the comparison of BMI across diets and by length of adherence to the specific diet (Objective 2) was 8226 participants. The characteristics of the restricted sample were similar to the original sample (data not shown).

Height and weight values within the 1-99 percentiles of data generated by sex for the National Health and Nutrition Examination Survey 2011-2014 were considered plausible in our sample ${ }^{(23)}$. Weight status was defined using the Center for Disease Control's cut-points for normal, overweight and obese based on $\mathrm{BMI}^{(24)}$.

Diet groups were combined based on self-identification and/or similarity of included/excluded or avoided foods, 
Table 1 Basic principles of diet groups captured in the Adhering to Dietary Approaches for Personal Taste (ADAPT) Feasibility Survey

\begin{tabular}{|c|c|c|}
\hline Self-identified diet* & Reduces or eliminates & Does include \\
\hline Try to eat healthy (TTEH) & & $\begin{array}{l}\text { No external practices/guidelines exist for this } \\
\text { group, respondents who selected this diet might } \\
\text { mean a variety of different eating patterns }\end{array}$ \\
\hline $\begin{array}{l}\text { Whole food, plant-based } \\
\text { (WFPB) }\end{array}$ & $\begin{array}{l}\text { All meat (red, poultry, fish), dairy, processed } \\
\text { food, added sugar, added oil, added/high } \\
\text { salt }\end{array}$ & $\begin{array}{l}\text { Whole grains, fruits, vegetables, legumes, nuts } \\
\text { and seeds }\end{array}$ \\
\hline Vegan and raw vegan (vegan) & $\begin{array}{l}\text { All meat (red, poultry, fish) and dairy } \\
\text { Raw vegans avoid cooked food }\end{array}$ & $\begin{array}{l}\text { Whole grains, fruits, vegetables, legumes, nuts } \\
\text { and seeds. Some vegans avoid processed food, } \\
\text { some eat a lot of it } \\
\text { Raw vegan emphasises raw vegetables, fruits, } \\
\text { nuts and seeds, soaked grains }\end{array}$ \\
\hline Paleo & Grains, dairy, legumes and processed foods & Meat, fish, vegetables, some fruits, nuts/seeds \\
\hline $\begin{array}{l}\text { Vegetarian and pescatarian } \\
\text { (vegetarian) }\end{array}$ & $\begin{array}{l}\text { Meat, including red meat, poultry and usually } \\
\text { fish }\end{array}$ & $\begin{array}{l}\text { Whole grains, fruits, vegetables, legumes, nuts } \\
\text { and seeds. Does not 'emphasise', but many } \\
\text { vegetarians do eat processed foods. Some } \\
\text { people may or may not eat eggs and cheese. } \\
\text { Pescatarians include fish }\end{array}$ \\
\hline $\begin{array}{l}\text { Whole food (combined from } \\
\text { those who selected 'whole } \\
\text { food', 'Mediterranean' and } \\
\text { 'locavore/local diet') }\end{array}$ & Processed foods & $\begin{array}{l}\text { Meat, dairy, fish, whole grains, fruits, vegetables, } \\
\text { legumes, nuts and seeds }\end{array}$ \\
\hline Weston A. Price (WAP) diet & $\begin{array}{l}\text { Processed foods, industrial oils, pasteurised } \\
\text { dairy, conventionally raised animal products }\end{array}$ & $\begin{array}{l}\text { Meat (emphasises pasture-raised and includes } \\
\text { organ meat, skin, bones, etc.), fish with skin, } \\
\text { non-pasteurised, full-fat dairy (especially butter), } \\
\text { egg with yolks, vegetables cooked with butter, } \\
\text { fruits raw or cooked with added fat, whole } \\
\text { grains, legumes, nuts, bone broth }\end{array}$ \\
\hline Low-carb & $\begin{array}{l}\text { Flour, sugar, refined grains, limited fruit, } \\
\text { starchy vegetables }\end{array}$ & $\begin{array}{l}\text { Meat, dairy, vegetables and some fruit, nuts/seeds. } \\
\text { Whole grains and starchy vegetables may be } \\
\text { limited (a variety of different low-carb } \\
\text { approaches may be captured in this group) }\end{array}$ \\
\hline
\end{tabular}

*In addition to the food summarised in this table, many of these diet groups also make specific supplement recommendations.

Imagine that you were chatting casually about your diet with someone you met in anelevator. Would you use any of the following terms to describe what you typically eat? It's okay if your diet doesn't 100\% match what these diets are 'supposed to be.'Please choose the onethat best matches what you would say, or 'Other diet' if you follow a diet that is not listed here (you can give your own description in the space provided):

O No particular diet / I haven't followed any diet

O No particular diet, but I have tried to eat healthy

O Mediterranean-type diet

O Paleolithic-type diet

O Vegan diet

O Raw vegan diet

O Vegetarian diet

O Pescatarian diet

O Gluten-free diet

O Whole food diet

O Whole food, plant-based diet

O Locavore / local food diet

O Weston A. Price diet

O High-protein diet

O Low-carb diet

O Low-fat diet

O Dairy-free

O Doctor/practitioner recommended (diabetic sugar-free diet, DASH, NCEP, low-calorie, orother)

O Other diet (the diet I have followed is not listed here)

Prefer not to answer

Fig. 1 Current diet captured in the Adhering to Dietary Approaches for Personal Taste (ADAPT) Feasibility Survey 
specifically fruits and vegetables, whole grains, animal food $v$. plant food, dairy, meat and refined foods. In addition, similar dietary groups with small numbers were collapsed into larger groups ${ }^{(21)}$. For example, respondents who selected the diet choice 'low-fat' ( $n$ 25) were combined with the larger group 'TTEH'. The final categories were as follows: whole food, plant-based (WFPB) ( $n$ 2344; 26\%), vegan (including raw vegan) ( $n 1763$; $20 \%$ ), Paleo ( $n 1326 ; 15 \%)$, TTEH ( $n 1048 ; 12 \%$ ), vegetarian and pescatarian ( $n 883 ; 10 \%)$, whole food (including Mediterranean and 'locavore') ( $n 754 ; 8 \%$ ), Weston A. Price (WAP) $(n 493 ; 5 \%)$ and low-carb ( $n$ 408; $4 \%)$. Those who selected TTEH were presented with a follow-up question asking which dietary behaviours they practice to 'try to eat healthy', and participants could select multiple dietary behaviours (see online supplementary material, Supplemental Fig. 1). Time following each diet was collapsed into four categories: $<6$ months, 6 months1 year, $1-5$ years, $>5$ years, as well as a dichotomous grouping of $<1$ year or $\geq 1$ year.

Demographic and descriptive health data captured included gender, age (seven categories 18-24, 25-34, 35-44, 45-54, 55-64, 65-74 and 75+ years), height (feet and inches), weight (lbs), race (White, Black or African American, American Indian or Alaska Native, Asian, Native Hawaiian or Other Pacific Islander and Other multiracial), ethnicity (Hispanic/non-Hispanic), ever diagnosed with a variety of health conditions $(y / n)$, currently diagnosed as overweight or obese $(\mathrm{y} / \mathrm{n})$, US residency $(\mathrm{y} / \mathrm{n})$ and, if applicable, US-based zip code. Age categories were collapsed for analysis into 18-34, 35-54 and 55+ years.

In addition to self-identifying their diet, participants were asked about dietary practices and lifestyle habits, including supplement use, past diet and how long they had followed their current diet. Specific supplements consumed were asked as a follow-up question for those who answered 'yes' to taking any supplements. Not asked were which specific single-nutrient or multi-nutrient supplements were taken. No data on prescription diet pills or other medications were collected.

Physical activity data were available on a subgroup of participants ( $n 3352$ participants) who completed the International Physical Activity Questionnaire short form ${ }^{(25)}$, which was an optional fill-in questionnaire. The sample size was further reduced to 3114 by restricting to those with valid BMI data. A continuous score of Metabolic-Equivalent (MET) minutes per week as well as categorical variables for low, moderate and high activity were generated according to International Physical Activity Questionnaire protocol.

\section{Statistical methods}

SAS statistical software (Version 9.4; SAS Institute) was used for all analyses. Descriptive statistics were generated for demographic and lifestyle characteristics for the total sample and by self-identified diet group. Continuous data are presented as means and $95 \% \mathrm{CI}$, and categorical data are presented as $n$ and (\%).

Due to right-skewed distribution, BMI values were log transformed prior to analyses. General linear models were used to estimate least square means adjusted for age, sex, US residency, time on diet and medication use for the following conditions: high cholesterol, high blood pressure, type 2 diabetes, cancer and gastrointestinal issues. Results are presented as geometric means and 95\% CI. The mean BMI among those on their diet for $<1$ year and $\geq 1$ year were compared within each diet group. A Bonferroni adjustment for multiple comparisons was applied ( $n 8$ ) yielding a critical value of 0.00625 for these analyses. A sensitivity analysis was conducted on the subset of participants who had physical activity data ( $n$ 3114) to assess if physical activity confounded the relationship between time on diet and BMI (see online supplementary material, Supplemental Table 2). BMI for each diet group overall was compared using TTEH as a reference group, as well as BMI for each diet group within each time on diet group ( $<1$ year, $1-5$ years and $>5$ years). TTEH was used as the reference group to represent a more non-specific eating pattern. Tukey's Honestly Significant Differences were applied to adjust for multiple comparisons in these analyses.

\section{Results}

A comparison of the demographic and self-reported health characteristics across diets is presented in Table 2 . Of the total sample of 9019 respondents, participants were $82 \%$ female, $93 \%$ White and $96 \%$ non-Hispanic. A greater proportion of participants were aged between 35 and 54 years ( $46 \%$ ), followed by $\geq 55$ years (33\%) and 18-34 years (22\%). The WFPB group had the smallest proportion (16\%) of those $18-34$ years while the vegan group had the largest $(26 \%)$. The Paleo group had the smallest proportion $(21 \%)$ of those $\geq 55$ years while the WFPB group had the largest ( $42 \%$ ). The majority of respondents (84\%) who took the survey reported living in the USA. Twenty-six percent of participants ( $n$ 9019) reported a current physician diagnosis of obesity or overweight, with the lowest rate observed in WAP (14\%) and highest among TTEH (40\%). Among those with BMI data ( $n$ 8226), $3 \%$ were classified as underweight, $55 \%$ normal weight, $24 \%$ overweight and $18 \%$ obese based on self-reported weight and height data.

The distribution of time following current self-identified diet was $12 \%$ (less than 6 months), $13 \%$ (6 months to 1 year), $49 \%$ ( $1-5$ years) and $27 \%$ (>5 years). The TTEH and vegetarian groups had the smallest proportion (34\%) following their diet for 1-5 years, and the Paleo group had the largest (62\%). The Paleo group also had the smallest proportion ( $9 \%$ ) within the $>5$ years category. 


\begin{tabular}{|c|c|c|c|c|c|c|c|c|c|}
\hline & Overall & WFPB & Vegan & Paleo & TTEH & Vegetarian & Whole food & WAP & Low-carb \\
\hline Diet followers $(n)$ & 9019 & 2344 & 1763 & 1326 & 1048 & 883 & 754 & 493 & 408 \\
\hline$\%$ of total & - & 26 & 20 & 15 & 12 & 10 & 8 & 5 & 5 \\
\hline \multicolumn{10}{|l|}{ Gender } \\
\hline Male (\%) & 18 & 19 & 18 & 21 & 14 & 11 & 12 & 17 & 31 \\
\hline Female (\%) & 82 & 81 & 82 & 79 & 86 & 89 & 88 & 83 & 69 \\
\hline \multicolumn{10}{|l|}{ Age group } \\
\hline $18-34(\%)$ & 22 & 16 & 26 & 25 & 23 & 22 & 25 & 20 & 21 \\
\hline $35-54(\%)$ & 46 & 42 & 44 & 54 & 48 & 48 & 45 & 39 & 42 \\
\hline $55+(\%)$ & 33 & 42 & 30 & 21 & 29 & 30 & 29 & 41 & 37 \\
\hline Hispanic (\%) & 4 & 4 & 4 & 5 & 5 & 5 & 4 & 4 & 2 \\
\hline Race (\% White) & 93 & 94 & 93 & 93 & 91 & 92 & 93 & 94 & 93 \\
\hline \multicolumn{10}{|l|}{ Region } \\
\hline Northeast (\%) & 14 & 13 & 12 & 12 & 19 & 17 & 17 & 16 & 12 \\
\hline South (\%) & 19 & 20 & 16 & 20 & 18 & 22 & 17 & 21 & 17 \\
\hline Midwest (\%) & 14 & 14 & 13 & 13 & 15 & 12 & 14 & 17 & 11 \\
\hline West (\%) & 22 & 23 & 23 & 25 & 20 & 20 & 21 & 27 & 18 \\
\hline Pacific (\%) & 1 & 1 & 1 & 1 & 1 & 1 & 0 & 1 & 0 \\
\hline Unknown US state (\%) & 14 & 15 & 13 & 12 & 15 & 15 & 16 & 15 & 14 \\
\hline Non-US country & 16 & 15 & 23 & 17 & 13 & 15 & 14 & 4 & 27 \\
\hline \multicolumn{10}{|l|}{ Time on diet $^{\star}$} \\
\hline Less than 6 months (\%) & 12 & 13 & 12 & 13 & 9 & 9 & 9 & 3 & 22 \\
\hline 6 months to 1 year $(\%)$ & 13 & 14 & 11 & 17 & 12 & 9 & 10 & 8 & 21 \\
\hline $1-5$ years $(\%)$ & 49 & 55 & 50 & 62 & 34 & 34 & 47 & 48 & 45 \\
\hline More than 5 years $(\%)$ & 27 & 17 & 27 & 9 & 45 & 48 & 33 & 42 & 12 \\
\hline \multicolumn{10}{|l|}{ Supplement use } \\
\hline Yes (\%) & 85 & 83 & 86 & 90 & 79 & 81 & 84 & 92 & 91 \\
\hline No $(\%)$ & 15 & 17 & 14 & 10 & 21 & 19 & 16 & 8 & 9 \\
\hline \multicolumn{10}{|l|}{ Past or current diagnosis of any health condition $\ddagger, \S^{*}$, } \\
\hline Yes $(\%)$ & 67 & 68 & 59 & 72 & 70 & 64 & 67 & 64 & 76 \\
\hline No/did not select (\%) & 33 & 32 & 41 & 28 & 30 & 36 & 33 & 36 & 24 \\
\hline Current or previous diagnosis of OW†† or OB†† (\%) & 26 & 24 & 21 & 23 & 40 & 30 & 29 & 14 & 35 \\
\hline \multicolumn{10}{|l|}{ Weight status among followers $<1$ year } \\
\hline Overweight†† (\%) & - & 22 & 21 & 27 & 26 & 27 & 25 & 24 & 35 \\
\hline Obeset† (\%) & - & 36 & 26 & 32 & 50 & 40 & 36 & 16 & 41 \\
\hline \multicolumn{10}{|l|}{ Weight status among followers $\geq 1$ year } \\
\hline Overweight (\%) & - & 20 & 19 & 28 & 27 & 25 & 25 & 21 & 31 \\
\hline Obese (\%) & - & 9 & 9 & 13 & 27 & 18 & 14 & 8 & 20 \\
\hline \multicolumn{10}{|l|}{ Medication usełł } \\
\hline Cholesterol (\%) & 4 & 4 & 2 & 2 & 7 & 5 & 4 & 0 & 7 \\
\hline High blood pressure (\%) & 8 & 8 & $\overline{6}$ & $\overline{5}$ & 11 & 10 & 7 & 3 & 11 \\
\hline Type 2 diabetes $(\%)$ & 2 & 2 & 1 & 1 & 3 & 1 & 2 & 0 & 5 \\
\hline Cancer (\%) & 1 & 1 & 1 & 0 & 1 & 1 & 0 & 1 & 1 \\
\hline Gastrointestinal (\%) & 2 & 1 & 1 & 2 & 4 & 2 & 2 & 1 & 1 \\
\hline \multicolumn{10}{|l|}{ No. of $\operatorname{diet}(\mathrm{s})$ followed in the past } \\
\hline One $(\%)$ & 34 & 36 & 46 & 32 & 26 & 29 & 28 & 29 & 30 \\
\hline Two (\%) & 14 & 15 & 13 & 15 & 14 & 9 & 15 & 17 & 11 \\
\hline Three or more (\%) & 16 & 15 & 13 & 18 & 16 & 11 & 21 & 23 & 19 \\
\hline
\end{tabular}


A large proportion of WAP respondents (42\%) reported following their diet for more than 5 years.

A total of $67 \%$ ( $n$ 6013) of participants responded 'yes' to having a current or past diagnosis of any health condition with $53 \%$ of $18-34$ years, $67 \%$ of $35-54$ years and $75 \%$ of $55+$ years reporting a health condition. The sample reported low medication use, with only $8 \%$ reporting blood pressure medication and $4 \%$ reporting cholesterol medication. Overall, a total of $34 \%$ reported following one other diet in the past ( $n 3077), 14 \%$ had followed two $(n 1227)$ and $16 \%$ had followed three or more ( $n$ 1425).

In the subsample of 3114 participants who completed the physical activity questions and had a valid BMI, the overall median MET minutes per week was 3108 (interquartile range (IQR): 1836-5154). In this subsample, $63 \%$ of respondents reported engaging in high physical activity defined by International Physical Activity Questionnaire for an average of at least $1 \mathrm{~h}$ or more of moderate or high intensity activity per day ${ }^{(25)}$. Across diet groups, the range was $1-5 \%$ low activity ( $1 \%$ for low-carb; $5 \%$ for vegetarian), $30-44 \%$ moderate (30 \% for WAP; $44 \%$ for TTEH) and 54-68\% high (54\% TTEH; 68\% WAP) (Table 2).

In the overall sample, we saw significant percentage differences in mean BMI for each diet group relative to TTEH $(P<0.001$ for all; Fig. 2$)$. When comparing those who reported following their diet for $\geq 1$ year $v$. $<1$ year (Table 3), the following four diet groups' mean BMI were significantly lower among those on their diets for $\geq 1$ year: WFPB $\left(25.9 v .23 .4 \mathrm{~kg} / \mathrm{m}^{2} ; P<0.001\right)$, vegan $(24.5 v$. $\left.23.2 \mathrm{~kg} / \mathrm{m}^{2} ; P=0.002\right)$, whole food $\left(26.1 v .24 .0 \mathrm{~kg} / \mathrm{m}^{2}\right.$; $P=0.002)$ and low-carb $\left(29.1 v .24 .8 \mathrm{~kg} / \mathrm{m}^{2} ; P<0.001\right)$. In the sensitivity analysis restricted to the subset of participants with available physical activity data ( $n 3114$ ), additionally adjusting for physical activity did not attenuate the results (see online supplementary material, Supplemental Table 2), suggesting that our main analysis is unlikely to be confounded by physical activity.

Among those who reported following their diet for 1-5 years, mean BMI were significantly lower among all diet groups compared with TTEH (Table 4). Mean BMI were TTEH $\left(26.4 \mathrm{~kg} / \mathrm{m}^{2}\right)$, WFPB $\left(23.2 \mathrm{~kg} / \mathrm{m}^{2} ; P<0.001\right)$, vegan $\left(23.5 \mathrm{~kg} / \mathrm{m}^{2} ; \quad P<0.001\right), \quad$ Paleo $\quad\left(24.6 \mathrm{~kg} / \mathrm{m}^{2}\right.$; $P<0.001)$, vegetarian $\left(25.0 \mathrm{~kg} / \mathrm{m}^{2} ; P=0.004\right)$, whole food $\left(24.6 \mathrm{~kg} / \mathrm{m}^{2} ; P<0.001\right)$,WAP $\left(23.5 \mathrm{~kg} / \mathrm{m}^{2} ; P<0.001\right)$ and low-carb $\left(24.7 \mathrm{~kg} / \mathrm{m}^{2} ; P=0.002\right)$.

Among those who reported following their diet for more than 5 years, mean BMI were significantly lower compared with TTEH $\left(26.0 \mathrm{~kg} / \mathrm{m}^{2} ; P<0.001\right)$ in the following groups: WFPB $\left(22.4 \mathrm{~kg} / \mathrm{m}^{2} ; P<0.001\right)$, vegan $\left(22.6 \mathrm{~kg} / \mathrm{m}^{2} ; P<0.001\right)$, Paleo $\left(23.9 \mathrm{~kg} / \mathrm{m}^{2} ; P=0.001\right)$, vegetarian $\left(24.5 \mathrm{~kg} / \mathrm{m}^{2} ; P<0.001\right)$, whole food $\left(24.3 \mathrm{~kg} / \mathrm{m}^{2}\right.$; $P<0.001)$ and WAP $\left(23.2 \mathrm{~kg} / \mathrm{m}^{2} ; P<0.001\right)$. BMI for low-carb followers did not differ from the TTEH diet group. Similarly, mean BMI for those who reported 


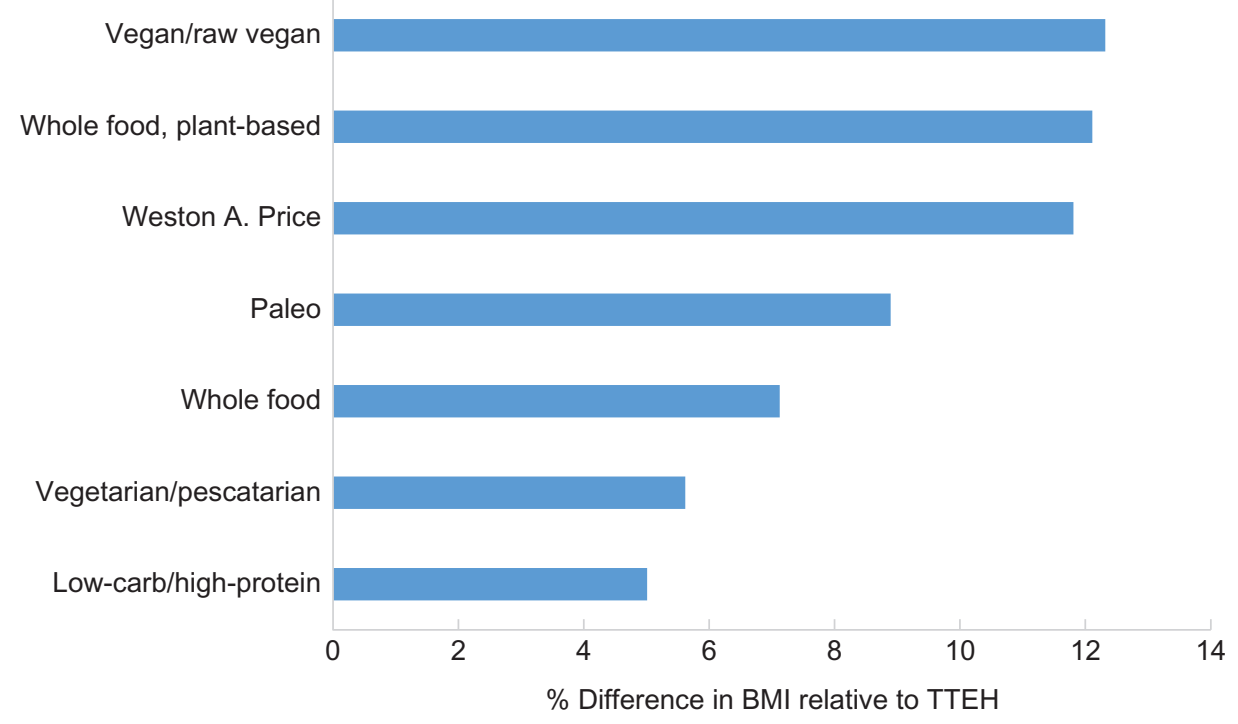

Fig. 2 (colour online) Comparison of overall adjusted mean BMI ${ }^{\star}, \dagger$ (percent differences) by diet group compared with TTEH. * $n 8226$. Excludes those with missing or invalid BMI ( $n 785$ due to missing or implausible height or weight data) and $(n 8)$ prefer not to answer responses to time on current diet; BMI means are adjusted for age, sex, US 'residency', time on diet and current medication use for the following conditions: high cholesterol, high blood pressure, type 2 diabetes, cancer and gastrointestinal. †Adjusted for Tukey's Honestly Significant Differences. All differences were statistically significant $(P<0.001)$

Table 3 Comparison of adjusted mean $(95 \% \mathrm{Cl}) \mathrm{BMI}^{\star}$ by time on diet $(<1$ year to $\geq 1$ year) within each diet group

\begin{tabular}{|c|c|c|c|c|c|c|c|c|c|c|}
\hline \multirow[b]{2}{*}{ Diets* } & \multirow[b]{2}{*}{8226} & \multicolumn{2}{|c|}{ Overall } & \multicolumn{3}{|c|}{ Less than 1 year } & \multicolumn{3}{|c|}{1 year or more } & \multirow{2}{*}{$\begin{array}{l}P \text { comparing mean BMI } \\
\text { by }<1 \text { year } v . \geq 1 \text { yeart }\end{array}$} \\
\hline & & Mean & $95 \% \mathrm{Cl}$ & $n$ & Mean & $95 \% \mathrm{Cl}$ & $n$ & Mean & $95 \% \mathrm{Cl}$ & \\
\hline TTEH & 968 & $27 \cdot 0$ & $26 \cdot 6,27 \cdot 4$ & 189 & 28.4 & $27 \cdot 1,29 \cdot 9$ & 779 & $26 \cdot 6$ & $25 \cdot 9,27 \cdot 3$ & 0.012 \\
\hline WFPB & 2141 & 23.7 & $23 \cdot 5,24 \cdot 0$ & 584 & 25.9 & $25 \cdot 3,26 \cdot 5$ & 1557 & 23.4 & $23 \cdot 1,23 \cdot 8$ & $<0.001$ \\
\hline Vegan & 1584 & 23.7 & $23 \cdot 4,23 \cdot 9$ & 349 & 24.5 & $23 \cdot 8,25 \cdot 2$ & 1235 & 23.2 & $22 \cdot 9,23 \cdot 6$ & 0.002 \\
\hline Paleo & 1202 & 24.6 & $24 \cdot 3,24.9$ & 349 & $25 \cdot 8$ & $24 \cdot 9,26 \cdot 6$ & 853 & 24.8 & $24 \cdot 3,25 \cdot 3$ & 0.06 \\
\hline Vegetarian & 814 & $25 \cdot 5$ & $25 \cdot 1,25 \cdot 9$ & 144 & $25 \cdot 9$ & $24 \cdot 5,27 \cdot 3$ & 670 & 24.7 & $24 \cdot 0,25 \cdot 4$ & 0.10 \\
\hline Whole food & 690 & $25 \cdot 1$ & $24 \cdot 7,25 \cdot 5$ & 129 & $26 \cdot 1$ & $24 \cdot 8,27 \cdot 5$ & 561 & $24 \cdot 0$ & $23 \cdot 3,24 \cdot 7$ & 0.002 \\
\hline WAP & 458 & $23 \cdot 8$ & $23 \cdot 4,24 \cdot 3$ & 45 & $24 \cdot 0$ & $22 \cdot 3,25 \cdot 8$ & 413 & 23.9 & $22 \cdot 8,25 \cdot 0$ & 0.88 \\
\hline Low-carb & 369 & $25 \cdot 7$ & $25 \cdot 1,26 \cdot 2$ & 154 & 29.1 & $27 \cdot 6,30 \cdot 7$ & 215 & $24 \cdot 8$ & $23 \cdot 9,25 \cdot 8$ & $<0.001$ \\
\hline
\end{tabular}

TTEH, try to eat healthy; WFPB, whole food, plant-based; WAP, Weston A. Price.

${ }^{*}$ Excludes those with missing or invalid BMI ( $n 785$ due to missing or implausible height or weight data) and ( $\left.n 8\right)$ prefer not to answer responses to time on current diet; BMI means are adjusted for age, sex, US 'residency', time on diet and current medication use for the following conditions: high cholesterol, high blood pressure, type 2 diabetes, cancer and gastrointestinal.

†Bonferroni correction for multiple comparisons (eight diet groups) yields a critical value of $0.00625(0.05 / 8)$.

following their diet for less than 1 year was lower in all popular diet groups than in the TTEH group, except for low-carb followers.

\section{Discussion}

To our knowledge, this survey is the first to capture data on a variety of popular diet followers, allowing for a comparison of participant characteristics and BMI across a wide range of self-identified diets with a sufficient sample size. We observed that compared with those participants who were reportedly trying to eat healthy, participants who reported following any particular diet had significantly lower mean BMI. We observed that mean BMI was lower among participants who had followed a WFBP, vegan, whole food or low-carb diet for more than 1 year compared with those who followed it for less than 1 year with mean difference ranging from $1.3 \mathrm{~kg} / \mathrm{m}^{2}$ (vegan) to $4.3 \mathrm{~kg} / \mathrm{m}^{2}$ (low-carb). We also observed that mean BMI among those who followed any particular diet, with the exception of low-carb, for 5 or more years ranged from 1.5 (vegetarian) to 3.6 (WFPB) $\mathrm{kg} / \mathrm{m}^{2}$ lower compared with TTEH. These data suggest, perhaps, that BMI is lower among those who made active decisions to adhere to well-defined diets particularly those that are more plant-based and/or limited highly processed foods, as well as those who follow specific diets for a longer time period. Based on a meta-analysis of observational studies, a $5 \mathrm{~kg} / \mathrm{m}^{2}$ higher BMI is associated with a $16 \%$ higher relative risk of sudden cardiac death incidence $^{(26)}$, and even a one unit higher BMI is associated with higher systolic blood pressure and total cholesterol in both 
Table 4 Comparison of adjusted mean $(95 \% \mathrm{Cl}) \mathrm{BMI}^{\star}$ by diet group stratified by time on diet and compared with TTEH group

\begin{tabular}{|c|c|c|c|c|c|c|c|c|c|c|c|c|c|}
\hline \multirow[b]{2}{*}{ Diet } & \multirow[b]{2}{*}{$n$} & \multicolumn{4}{|c|}{$<1$ year } & \multicolumn{4}{|c|}{$1-5$ years } & \multicolumn{4}{|c|}{$>5$ years } \\
\hline & & $n$ & $\mathrm{BMI}$ & $95 \% \mathrm{Cl}$ & $P+$ & $n$ & BMI & $95 \% \mathrm{Cl}$ & $P$ & $n$ & BMI & $95 \% \mathrm{Cl}$ & $P$ \\
\hline TTEH & 968 & 189 & $28 \cdot 8$ & $27 \cdot 8,29 \cdot 9$ & - & 338 & $26 \cdot 4$ & $25 \cdot 9,26 \cdot 9$ & - & 441 & $26 \cdot 0$ & $25 \cdot 4,26 \cdot 5$ & - \\
\hline WFPB & 2141 & 584 & $26 \cdot 7$ & $26 \cdot 1,27 \cdot 3$ & $<0.0001$ & 1173 & $23 \cdot 2$ & $22 \cdot 9,23.5$ & $<0.001$ & 384 & $22 \cdot 4$ & $21 \cdot 9,22 \cdot 8$ & $<0.001$ \\
\hline Vegan & 1584 & 349 & $25 \cdot 7$ & $25 \cdot 1,27 \cdot 0$ & $<0.0001$ & 798 & 23.5 & $23 \cdot 1,23 \cdot 8$ & $<0.001$ & 437 & $22 \cdot 6$ & $22 \cdot 2,23 \cdot 1$ & $<0.001$ \\
\hline Paleo & 1202 & 349 & $26 \cdot 2$ & $25 \cdot 5,27 \cdot 0$ & $<0.0001$ & 749 & $24 \cdot 6$ & $24 \cdot 2,24 \cdot 9$ & $<0.001$ & 104 & 23.9 & $23 \cdot 1,24 \cdot 8$ & 0.001 \\
\hline Vegetarian & 814 & 144 & $26 \cdot 9$ & $25 \cdot 9,28 \cdot 0$ & 0.005 & 286 & $25 \cdot 0$ & $24.5,25 \cdot 6$ & 0.004 & 384 & 24.5 & $24 \cdot 0,25 \cdot 0$ & $<0.001$ \\
\hline Whole food & 690 & 129 & $27 \cdot 1$ & $26 \cdot 0,28 \cdot 3$ & 0.014 & 333 & $24 \cdot 6$ & $24 \cdot 1,25 \cdot 2$ & $<0.001$ & 228 & $24 \cdot 3$ & $23 \cdot 6,24 \cdot 9$ & $<0.001$ \\
\hline WAP & 458 & 45 & 24.0 & $22 \cdot 4,25 \cdot 7$ & $<0.0001$ & 220 & 23.5 & $23 \cdot 0,24 \cdot 1$ & $<0.001$ & 193 & $23 \cdot 2$ & $22 \cdot 6,23 \cdot 9$ & $<0.001$ \\
\hline Low-carb & 369 & 154 & 28.0 & $27 \cdot 0,29 \cdot 1$ & 0.220 & 170 & $24 \cdot 7$ & $24 \cdot 1,25 \cdot 4$ & 0.002 & 45 & $26 \cdot 2$ & $24 \cdot 8,27 \cdot 6$ & $>0.99$ \\
\hline
\end{tabular}

TTEH, try to eat healthy; WFPB, whole food, plant-based; WAP, Weston A. Price.

${ }^{*} n 8226$, excludes those with missing or invalid BMI ( $n 785$ due to missing or implausible height or weight data) and ( $n 8$ ) prefer not to answer responses to time on current diet; $\mathrm{BMI}$ means are adjusted for age, sex, US 'residency' and current medication use for the following conditions: high cholesterol, high blood pressure, type 2 diabetes, cancer and gastrointestinal.

$\dagger P$-values are adjusted using Tukey's Honestly Significant Differences method for multiple comparisons.

men and women ${ }^{(27)}$. These data underscore the importance of our findings in understanding factors that may facilitate healthy weight loss and maintenance. Based on our ADAPT FS, we have designed a larger ADAPT Study (data collection ongoing) aimed at capturing a wide range of data on psychobiological, cultural, social and environmental predictors of long-term dietary adherence, in addition to self-reported dietary intake data.

Our previous analysis estimating theoretical food and nutrient levels of WFPB and vegan diets indicated that WFPB and vegan patterns were similar ${ }^{(28)}$, including high targets for vegetables, whole grains and legumes, no animal products, low levels of total and saturated fat, and a high level of fibre $(\sim 70 \mathrm{~g} / \mathrm{d})$. Consistent with findings from other cross-sectional studies ${ }^{(29-32)}$, we observed that followers of more plant-based diets, in particular vegan and WFPB, had the lowest BMI relative to other diet followers and also compared with those who TTEH (Fig. 2). In a cross-sectional analysis in a sample of 73308 adults from the Adventist Health Study II cohort, vegans had lower BMI $\left(24 \cdot 1 \mathrm{~kg} / \mathrm{m}^{2}\right)$ compared with vegetarians $\left(26 \cdot 1 \mathrm{~kg} / \mathrm{m}^{2}\right)$ and semi-vegetarians $\left(27.3 \mathrm{~kg} / \mathrm{m}^{2}\right)^{(33)}$. Similarly, in a recent cross-sectional analysis of 3475 Hispanic/Latino adults, in comparison to the non-vegetarian diet followers, BMI was significantly lower in vegan, followed by vegetarian and pescatarian adults ${ }^{(29)}$.

Emerging evidence from longitudinal studies shows that higher conformity to more plant-based diets is associated with less weight gain ${ }^{(13,34)}$, less gain in abdominal adiposity $^{(13)}$ and reduced risk of becoming overweight or obese $^{(34)}$. Noteworthy is the observation that weight gain is not mitigated in followers of plant-based diets when these diets are considered 'less healthy', that is, diets high in sugary foods and beverages, refined gains and desserts ${ }^{(35)}$. A meta-analysis of twelve randomised controlled trials, with a median of 18 weeks duration ( 8 weeks to 2 years), found that people assigned to vegetarian weight loss diets lost significantly more weight than those assigned to non-vegetarian diets ${ }^{(36)}$. Limited observational data on the long-term impact of following a Paleo diet on body weight exist, although a recent meta-analysis of eleven randomised controlled trials conducted over 2 weeks to 24 months suggests that the Paleo diet compared with the control diet led to greater reductions in body weight, BMI and waist circumference ${ }^{(16)}$. While sample sizes were small, these intervention diets typically eliminated added sugars and refined foods, while at the same time emphasising meat, fish and vegetables ${ }^{(16)}$.

We observed that BMI was higher among those who identified as 'trying to eat healthy', which captured several dietary behaviours, including eating more fruits and vegetables, drinking less sugar-sweetened beverages, eating less meat and eating fewer salty snacks. One possibility is that merely 'trying to eat healthy' may not be as effective at achieving or maintaining healthy body weight as subscribing to a more defined diet. Alternatively, participants who report following a specific diet may have been doing so specifically to manage or lose weight. We also observed lower mean BMI among those participants who had followed their diets for more than 1 year, suggesting that adherence to a diet is important in weight maintenance or loss. Albeit limited, there is some evidence to support that adherence to certain specific diets, irrespective of the principles of the diet, may be a more important determinant of weight loss than the diet itself ${ }^{(37,38)}$. A randomised controlled trial of five increasingly plant-based diets (spanning omnivorous to vegan), providing no instructions on energy restriction, found that those assigned to the vegan diet lost significantly more weight than the omnivorous, semi-vegetarian and pescatarian; however, among adherent participants only, all diets produced equivalent weight loss over 6 months ${ }^{(39)}$. Of note, the non-adherent vegan and vegetarian participants in this intervention lost significantly more weight than non-adherent omnivore participants ${ }^{(40)}$, thus suggesting that plant-based diets may be more effective targets for weight loss without full adherence. Given the duration of the interventions and poor follow-up outcomes of weight loss studies, future 
long-term studies of followers of all these diets are needed to determine whether consciously committing to any specific diet is associated with lower BMI over the lifespan.

As this study was designed to demonstrate feasibility, several limitations should be noted. Participants were primarily women (82\%) and White (93\%), limiting the generalisability of our findings, to primarily White women, consistent with observed response rates to other surveys ${ }^{(41,42)}$, including web-based surveys ${ }^{(1)}$. The self-selected nature of the cohort prevents knowing whether the followers in each diet group are representative of the followers in the general population, and, due to the sampling, they are unlikely to be representative with respect to sex, race, socioeconomic status, internet access or time following current diet. Selfreported data also increase the possibility of reporting bias, particularly with respect to body weight. The ADAPT FS was brief and did not capture data on actual dietary intake, socioeconomic status, behaviour or physical activity. Our current exposure is intentionally self-identified diet; thus, discrepancies may exist between researchers' perceptions of the self-identified label and actual food choices ${ }^{(43,44)}$. Furthermore, the cross-sectional nature of our survey did not allow for prospective identification of either (1) individuals who successfully lost weight following a particular dietary pattern or (2) 'serial dieters' (individuals who may try one diet after another).

One additional limitation not addressed in this analysis is that diet followers may be motivated to adhere to their diet for a variety of reasons, and these motivations may also influence eating habits ${ }^{(2)}$ and, accordingly, weight and $\mathrm{BMI}^{(10,45)}$. For example, vegans with health-related motivations reported eating more fruits and fewer sweets compared with vegans with ethical motivations ${ }^{(2)}$. In a general sample of adults, being female, older age, having normal BMI, regular exercise and higher intakes of fruits and vegetables were associated with higher odds of having a strong motivation to eat healthfully ${ }^{(45)}$. These are important considerations for future surveys, and we have aimed to address many of these limitations with our larger ongoing data collection in the main ADAPT Study. Preliminary analysis of data collected among individuals in the main ADAPT Study suggests that prevention and overall wellness are among the top motivations for following a particular diet, although other motivations were identified ${ }^{(46)}$.

The ADAPT FS has several strengths including capturing demographic and lifestyle characteristics data across a broad range of diet groups. Other strengths include the large sample size and relatively even distribution among age brackets, geographic origin in the USA and time following current diet. This survey captured self-identified diet, which enables future analyses on adherence to specific diet principles by comparing theoretical $v$. actual dietary intakes. Results on mean BMI across diet followers provide a relevant snapshot into possible outcomes for individuals who choose to adhere to a specific diet over the long-term.
Effective strategies to promote healthy weight loss and maintenance are urgently needed. Overweight and obesity are the most widespread public health problems in the USA, with approximately two-thirds of all Americans being overweight and half of those being obese ${ }^{(47)}$. In the USA, at the midcourse review of the Healthy People 2020 goals, it was noted that 'little or no detectable change' was observed with prevalence of adult obesity or daily consumption of vegetables $^{(48)}$. Adherence to diets that emphasise more plant foods and less refined foods, such as those identified in the ADAPT Study, may be effective strategies to promote weight loss and healthy weight maintenance.

\section{Conclusion}

Our findings suggest that BMI is lower among those participants who made active decisions to adhere to a specific diet, particularly more plant-based diets and/or specific diets limiting processed foods, compared with those who simply try to eat healthy, as well as those who follow intentional eating plans for a longer time period. However, these data indicate overweight and obesity may be less prevalent in our study respondents compared with the general US population. Health professionals who encounter individuals following a specific diet should be familiar with what is known about popular diet followers in practice, as these diets may facilitate healthy weight loss and maintenance. In future research, actual dietary intake data from recalls or records should be collected and recruitment strategies expanded to collect data on men, different ethnic groups and those reporting no particular diet.

\section{Acknowledgements}

Acknowledgements: The authors thank our recruitment partners who made the administration of this survey possible and to ADAPT FS study participants. Funding support: This work was supported by USDA ARS agreement No. 2012-38420-30200 (M.C.K., C.D.E.), USDA ARS agreement No. 58-1950-4-003 (A.H.L., G.R., P.F.J., K.A.L. and N.M.M.), Tufts Collaborates and the Lisa Wendel Memorial Foundation. Conflict of interest: M.C.K. is an unpaid member of the Board of Directors for the Plant-based Prevention of Disease Conference and currently receives consulting payments from the Plantrician Project. N.M.M. currently receives research funding from the Bell Institute of Health and Nutrition and ILSI North America. The other authors declare no conflict of interest. Authorship: M.C.K., G.R., K.A.L. and N.M.M. collected the data. M.C.K. analysed the data and wrote the first draft of the manuscript with oversight from G.R. and N.M.M. K.A.L. edited the manuscript. All authors reviewed and 
commented on subsequent drafts of the manuscript. Ethics of human subject participation: This study was conducted according to the guidelines laid down in the Declaration of Helsinki and all procedures involving research study participants were approved by the Tufts University Health Sciences Internal Review Board. Written informed consent was obtained from all subjects.

\section{Supplementary material}

For supplementary material accompanying this paper visit https://doi.org/10.1017/S10.1017/S1368980020001330

\section{References}

1. Schwartz DB \& Stapell HM (2013) Modern Cavemen? Stereotypes and reality of the ancestral health movement. $J$ Evol Health 1, 3.

2. Radnitz C, Beezhold B \& DiMatteo J (2015) Investigation of lifestyle choices of individuals following a vegan diet for health and ethical reasons. Appetite 90, 31-36.

3. Campos CL, Wood A, Burke GL et al. (2019) Dietary approaches to stop hypertension diet concordance and incident heart failure: the multi-ethnic study of atherosclerosis. Am J Prev Med 56, 819-826.

4. Batte MT, Hooker NH, Haab TC et al. (2007) Putting their money where their mouths are: consumer willingness to pay for multi-ingredient, processed organic food products. Food Policy 32, 145-159.

5. Nuti SV, Wayda B, Ranasinghe I et al. (2014) The use of Google trends in health care research: a systematic review. PLoS One 9, e109583.

6. Asher K, Green C, Gutbrod H et al. (2014) Study of Current and Former Vegetarians and Vegans. Washington, DC: Faunalytics.

7. International Food Information Council Foundation (2019) 2019 Food \& Health Survey. Washington, DC: International Food Information Council Foundation.

8. Buijsse B, Feskens EJ, Schulze MB et al. (2009) Fruit and vegetable intakes and subsequent changes in body weight in European populations: results from the project on Diet, Obesity, and Genes (DiOGenes). Am J Clin Nutr 90, 202-209.

9. Reynolds A, Mann J, Cummings J et al. (2019) Carbohydrate quality and human health: a series of systematic reviews and meta-analyses. Lancet 393, 434-445.

10. Schlesinger S, Neuenschwander M, Schwedhelm C et al. (2019) Food groups and risk of overweight, obesity, and weight gain: a systematic review and dose-response metaanalysis of prospective studies. Adv Nutr 10, 205-218.

11. Khan TA, Tayyiba M, Agarwal A et al. (2019) Relation of total sugars, sucrose, fructose, and added sugars with the risk of cardiovascular disease: a systematic review and doseresponse meta-analysis of prospective cohort studies. Mayo Clin Proc 94, 2399-2414.

12. US Department of Agriculture, Agricultural Research Service, Beltsville Human Nutrition Research Center, Food Surveys Research Group (Beltsville, MD) \& Centers for Disease Control and Prevention (CDC) (2017) National Center for Health Statistics (NCHS). National Health and Nutrition Examination Survey Data. Hyattsville, MD: US Department of Health and Human Services, Centers for Disease Control and Prevention [2007-2010]. https://wwwn.cdc.gov/nchs/
nhanes/ContinuousNhanes/Overview.aspx?BeginYear=2007 (accessed July 2017).

13. Chen Z, Schoufour JD, Rivadeneira F et al. (2019) Plantbased diet and adiposity over time in a middle-aged and elderly population: the Rotterdam study. Epidemiology 30, 303-310.

14. Franquesa M, Pujol-Busquets G, Garcia-Fernandez E et al. (2019) Mediterranean diet and cardiodiabesity: a systematic review through evidence-based answers to key clinical questions. Nutrients 11, 655.

15. Orlich MJ \& Fraser GE (2014) Vegetarian diets in the Adventist Health Study 2: a review of initial published findings. Am J Clin Nutr 100, 353s-358s.

16. de Menezes EVA, Sampaio HAC, Carioca AAF et al. (2019) Influence of Paleolithic diet on anthropometric markers in chronic diseases: systematic review and meta-analysis. Nutr J 18, 41.

17. Harvey C, Schofield GM, Zinn C et al. (2019) Lowcarbohydrate diets differing in carbohydrate restriction improve cardiometabolic and anthropometric markers in healthy adults: a randomised clinical trial. PeerJ 7, e6273.

18. Kim HS, Demyen MF, Mathew J et al. (2017) Obesity, metabolic syndrome, and cardiovascular risk in gluten-free followers without celiac disease in the United States: results from the national health and nutrition examination survey 2009-2014. Dig Dis Sci 62, 2440-2448.

19. Juul F, Martinez-Steele E, Parekh N et al. (2018) Ultraprocessed food consumption and excess weight among US adults. Br J Nutr 120, 90-100.

20. Wang Y \& Beydoun MA (2009) Meat consumption is associated with obesity and central obesity among US adults. Int $J$ Obes 33, 621-628.

21. Karlsen MC, Lichtenstein AH, Economos CD et al. (2018) Web-based recruitment and survey methodology to maximize response rates from followers of popular diets: the Adhering to Dietary Approaches for Personal Taste (ADAPT) feasibility survey. Curr Dev Nutr 2, nzy012.

22. Eysenbach G (2004) Improving the quality of Web surveys: the Checklist for Reporting Results of Internet E-Surveys (CHERRIES). J Med Internet Res 6, e34.

23. US Department of Agriculture, Agricultural Research Service, Beltsville Human Nutrition Research Center, Food Surveys Research Group (Beltsville, MD) \& Centers for Disease Control and Prevention (CDC) (2017) National Center for Health Statistics (NCHS). National Health and Nutrition Examination Survey Data. Hyattsville, MD: U.S. Department of Health and Human Services, Centers for Disease Control and Prevention [2011-2014]. https://wwwn.cdc.gov/nchs/ nhanes/ContinuousNhanes/Overview.aspx?BeginYear=2011 (accessed July 2017).

24. Centers for Disease Control and Prevention: About Adult BMI (2017). https://www.cdc.gov/healthyweight/assessing/ bmi/adult_bmi/index.html (accessed November 2017).

25. Maddison R, Ni Mhurchu C, Jiang Y et al. (2007) International Physical Activity Questionnaire (IPAQ) and New Zealand Physical Activity Questionnaire (NZPAQ): a doubly labelled water validation. Int J Behav Nutr Phys Act 4, 62.

26. Aune D, Schlesinger S, Norat T et al. (2018) Body mass index, abdominal fatness, and the risk of sudden cardiac death: a systematic review and dose-response meta-analysis of prospective studies. Eur J Epidemiol 33, 711-722.

27. Dudina A, Cooney MT, Bacquer DD et al. (2011) Relationships between body mass index, cardiovascular mortality, and risk factors: a report from the SCORE investigators. Eur J Cardiovasc Prev Rehabil 18, 731-742.

28. Karlsen MC, Rogers G, Miki A et al. (2019) Theoretical food and nutrient composition of whole-food plant-based and vegan diets compared to current dietary recommendations. Nutrients 11, 625 . 
29. Jaceldo-Siegl K, Estevez D, Fraser GE et al. (2019) Plantbased diets in Hispanic/Latino adult Adventists in the United States and their association with Body Mass Index. Am J Health Promot 33, 869-875.

30. Spencer EA, Appleby PN, Davey GK et al. (2003) Diet and body mass index in 38000 EPIC-Oxford meat-eaters, fish-eaters, vegetarians and vegans. Int J Obes Relat Metab Disord 27, 728-734.

31. Tonstad S, Butler T, Yan R et al. (2009) Type of vegetarian diet, body weight, and prevalence of type 2 diabetes. Diabetes Care 32, 791-796.

32. Newby PK, Tucker KL \& Wolk A (2005) Risk of overweight and obesity among semivegetarian, lactovegetarian, and vegan women. Am J Clin Nutr 81, 1267-1274.

33. Orlich MJ, Singh PN, Sabate J et al. (2013) Vegetarian dietary patterns and mortality in Adventist Health Study 2. JAMA Intern Med 173, 1230-1238.

34. Japas C, Knutsen S, Dehom S et al. (2014) Body mass index gain between ages 20 and 40 years and lifestyle characteristics of men at ages 40-60 years: the Adventist Health Study-2. Obes Res Clin Pract 8, e549-e557.

35. Gomez-Donoso C, Martinez-Gonzalez MA, Martinez JA et al. (2019) A provegetarian food pattern emphasizing preference for healthy plant-derived foods reduces the risk of overweight/obesity in the SUN cohort. Nutrients 11, 1553 .

36. Huang RY, Huang CC, Hu FB et al. (2016) Vegetarian diets and weight reduction: a meta-analysis of randomized controlled trials. J Gen Intern Med 31, 109-116.

37. Dansinger ML, Gleason JA, Griffith JL et al. (2005) Comparison of the Atkins, Ornish, Weight Watchers, and Zone diets for weight loss and heart disease risk reduction: a randomized trial. JAMA 293, 43-53.

38. Alhassan S, Kim S, Bersamin A et al. (2008) Dietary adherence and weight loss success among overweight women: results from the A to $\mathrm{Z}$ weight loss study. Int J Obes 32, 985-991.
39. Turner-McGrievy GM, Davidson CR, Wingard EE et al. (2015) Comparative effectiveness of plant-based diets for weight loss: a randomized controlled trial of five different diets. Nutrition 31, 350-358.

40. Moore WJ, McGrievy ME, Turner-McGrievy GM (2015) Dietary adherence and acceptability of five different diets, including vegan and vegetarian diets, for weight loss: the New DIETs study. Eat Behav 19, 33-38.

41. Cramer H, Kessler CS, Sundberg Tet al. (2017) Characteristics of Americans choosing vegetarian and vegan diets for health reasons. J Nutr Educ Behav 49, 561-567, e561.

42. Smith G (2008) Does gender influence online survey participation? A record-linkage analysis of university faculty online survey response behavior. ERIC Document Reproduction Service No ED 501717.

43. Rothgerber H (2014) A comparison of attitudes toward meat and animals among strict and semi-vegetarians. Appetite 72, 98-105.

44. Rajpoot P, Sharma A, Harikrishnan S et al. (2015) Adherence to gluten-free diet and barriers to adherence in patients with celiac disease. Indian J Gastroenterol 34, 380-385.

45. Naughton P, McCarthy SN \& McCarthy MB (2015) The creation of a healthy eating motivation score and its association with food choice and physical activity in a cross sectional sample of Irish adults. Int J Behav Nutr Phys Act 12, 74 .

46. Miki A, Karlsen M, Livingston K et al. (2019) Motivations to adopt plant-based diets: data from the Adhering to Dietary Approaches for Personal Taste (ADAPT) Study (P16-024-19). Curr Dev Nutr 3, nzz050-P16.

47. Yang L \& Colditz GA (2015) Prevalence of overweight and obesity in the United States, 2007-2012. JAMA Int Med 175, 1412-1413.

48. Healthy People 2020: Progress Made toward Targets for Leading Health Indicators. Midcourse Review. https:// www.healthypeople.gov/2020/data-search/midcourse-review/ lhi (accessed August 2017). 